\title{
Computational Approaches for Basic Design Education: Pedagogical Notes Based on an Intense Student Workshop
}

\author{
- Güzden Varınlıglu \\ Assistant Professor, Izmir University of \\ Economics, Turkey \\ guzdenv@gmail.com \\ - Sema Alaçam \\ Assistant Professor, Istanbul Technical \\ University, Turkey \\ semosphere@gmail.com \\ - Süheyla Müge Halıcı \\ Master Student, Istanbul Technical University, \\ Turkey \\ smhalici@hotmail.com
}

\begin{abstract}
This paper categorizes the implementation of specifically CAD/CAM into architectural design education following two main pedagogical models: Discrete and Integrated. In order to evaluate the integrated pedagogical model, the authors conducted a oneday-workshop for basic design students (34 first-year, two second-year) in April 2015, at the Faculty of Fine Arts \& Design at Izmir University of Economics in Turkey. The goal of this work is to discuss the potential and limitations of integrated pedagogical model of CAD/CAM introduction, particularly supported by visual scripting environment (VSE).
\end{abstract}

Keywords: Basic Design, Digital Fabrication, Curriculum, Student Workshop, Visual Scripting Environment (VSE)

\section{Introduction}

"First we build the tools, then they build us" Marshall McLuhan.

Over the last decade, the use of digital technologies has progressively become a common tool for architectural discourse and the education of architecture students. Ready access to open-source parametric and algorithmic design tools, and fabrication technology, changes and evolves the architectural design process by challenging the traditional teaching methods. In architectural education, it is still common to have the basic design course based on actual materials and hand-skills that is supported by additional computer aided design and drafting courses. This education strategy includes computational tools at the later stages of the architectural education curriculum. There have been several studies (Celani, 2012; Duarte et al, 2011; Gül et al., 2014; Liapi et al., 2012; Mark et.al., 2003; Oxman, 2006; Valdes et.al., 2013) on the implementation of computational design tools in the design education, however, there are few studies on the outcome of students' learning through digital fabrication courses and/or which skills are required to implement CAD/ CAM tools in the junior year of architectural design education. How students interact with the computer in their first year of architectural education substantially shapes the remainder of their education. With this in mind, and in order to evaluate the computational approach for basic design education, this paper aims to discuss the interrelations between the process and the outcome of the innovative student work from Art and Design Studio-1, the one-day intense digital fabrication workshop held at Izmir University of Economics.

In this paper we categorize the implementation of specifically CAD/CAM into the architectural design education following two main pedagogical models: discrete and integrated. Discrete pedagogical model refers to a curriculum in which CAD/CAM courses are conducted independently of the main architectural design studio. The integrated pedagogical model refers to embedding digital technologies in the traditional design studio. In respect to integration concept, Oxman (2006) states that:

"Theories and methods of digital design can no longer be conceptualized as the merging of computational tools with conventional formulations of design."

Considering Oxman's (2006) statement, our study covers introducing algorithms of magnetism via VSE. The algorithm of magnetism was chosen due to its roots depending on a dynamic and an observable physical experience. Therefore, our integrated pedagogical model differs from merely introducing the work flow of CAD/CAM in the design studios.

Each teaching model has its limitations. One of the main limitations in keeping digital technology as a discrete skill-set saw difficulty implementing the skills into the design process/ studio for first year students prior to graduation projects. For instance, in the design studios of various Turkish schools of architecture, most students tend to use CAD tools merely 


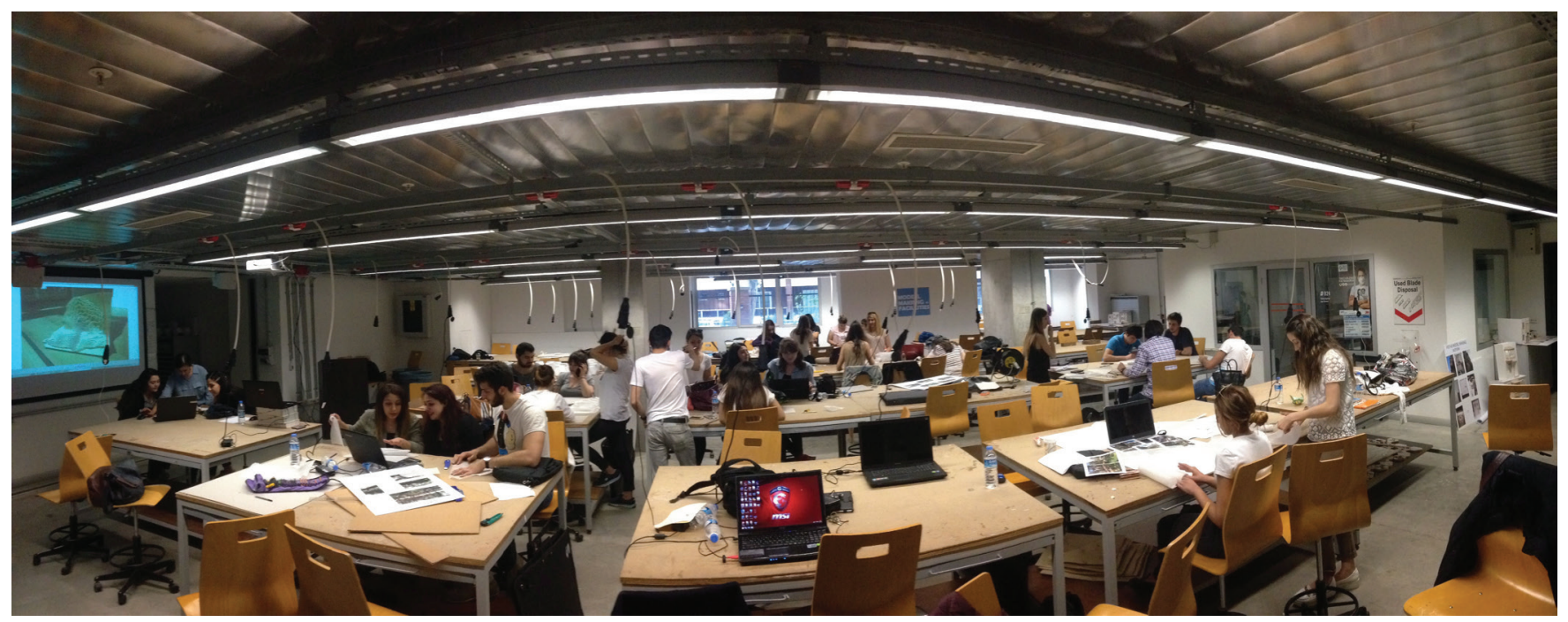

Figure 1: View from the studio.

for representation in their graduation projects, as we have observed especially in the last 5 years.

Moreover, students conceive the digital tools and computer skills as a separate entity, lending difficulty to learning often complex digital media interfaces. Also, the skill set conducted in the basic design studio is poorly applied to computerized design outcomes. In other words, students forget the skill sets learned in the basic design course and often leads to poor results in computer aided design problems. On the other hand, "togetherness of the digital technologies" or integrated models, do not mean directly attaching the CAD/CAM technologies to design studios. Thus, similar to Oxman's (2006) statement, new pedagogical explorations are needed to intensify the togetherness of the digital technologies and their implementation into basic design. Also the experience of algorithmic thinking in Carpo's (2011) terms 'the new alphabet' of the digital era, requires new pedagogical perspectives.

In addition to this, it is crucial to include digital technologies in the basic design education in order to link the observable relations/algorithms of the physical world and their abstract representations in the digital environment. The integration of digital tools in the early design process can facilitate mock-up fabrication and allow novice designers to have more meaningful influence in the outcome. When students are encouraged to integrate digital tools at an elementary design stage, they show more motivation to solve advanced design problems by employing more complex interfaces in their later years of education. Thus, the argument of integrating digital tools to the design curriculum is valid for the junior year students, excluding graduate level. The assumptions and findings can differ for the second generation of "digital natives" (Prensky, 2001).

To investigate the integrated pedagogical model, the authors conducted a one-day-workshop for basic design studentsat theFaculty of Fine Arts\& Designat Izmir University of Economics. In this paper, the first section investigates proper curricular goals and the teaching methodologies within the context of the workshop. The second section analyzes student outcomes within a framework of digital fabrication pedagogy by highlighting the parametric design skills gained by students. These sections lead to a conclusive review of the work from a standpoint of innovation in basic design education and showcases how the CAD/CAM pedagogies provide a rich context for students' learning and research.

\section{Workshop on the design of a playground using magnetic relations}

In the 10th year anniversary of the Department of Architecture at Izmir University of Economics, the panel entitled TRANS_ARCH_EDU aimed to provide a shared platform for exploring approaches to address new directions in architectural education. The participants were asked to focus on the acute issues at the intersection of two thematic sessions, one being concerned with emerging computational design approaches and the other with interdisciplinary frameworks in architectural education. The panel was dedicated to fostering a constructive dialogue between leading academics and practitioners concerned with ideas that will take architectural education forward. Our workshop was influenced by a second theme on the "Role of Computational Design in Architecture". Advances in digital computing not only challenge traditional ways of conceptualizing buildings but also impact the nature of the relationship between design, construction, and habitation. The theme, however, requires further elaboration and the participants were asked to consider the role of computational design within a framework that links emerging practices in the profession with the relevant strategies adopted in architectural education. The guiding questions posed within this session were as follows:

- How do advances in digital computation shape the 

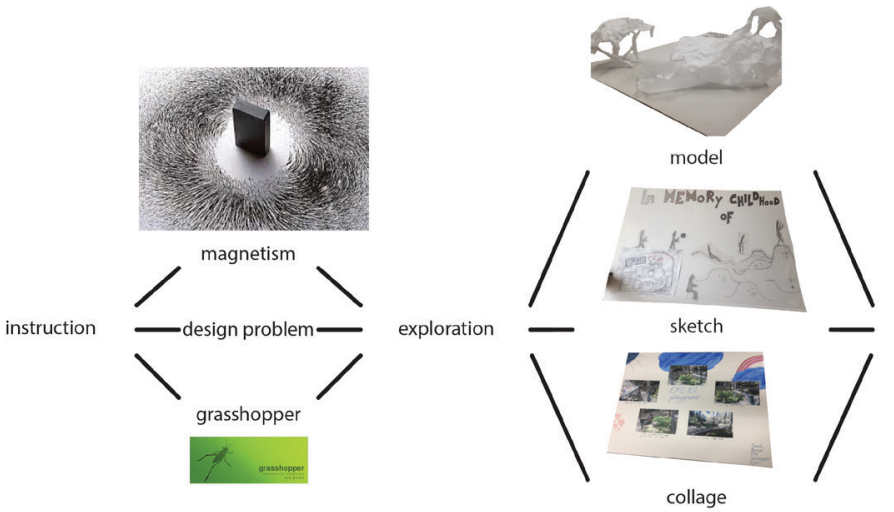

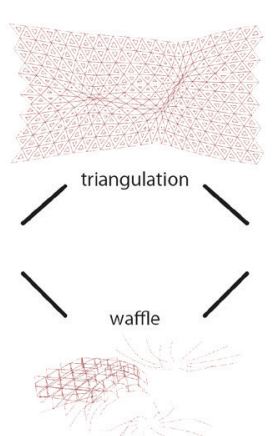

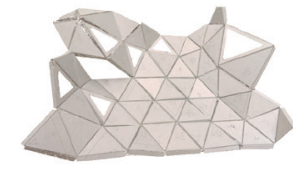

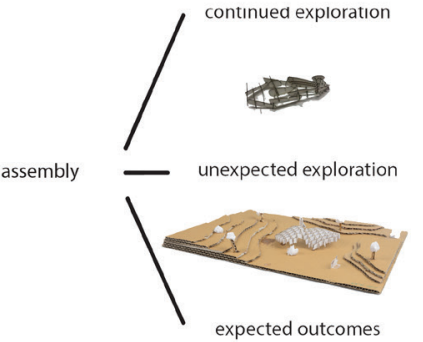

Figure 2: Process of the workshop.

approaches to architectural education?

- How does the academic community react to the developments in design computing?

- What are the concerns about computational design within both practice based and academic communities?

During ten years of design education in the Department of Architecture at Izmir University of Economics, the main objective has been an interdisciplinary design education for first year students in the design fields in the Faculty of Fine Arts \& Design. A single-unit basic design studio curriculum brought students from Fashion, Visual Communication \& Design, Interior Design and Industrial Design together to assess the same design problem from different design perspectives. Conducted as part of the first year studio, the challenge of our workshop was to offer the same spatia design problem to all students from 34 first-year and two second-year, having no prior experience in a visual scripting environment (VSE) nor digital fabrication. Given an outdoor park scenario, the students were asked to design a playground for children by deconstructing and exploring a holistic algorithm of a magnetic field. As an exercise, the problem of designing a playground was ideal, as the students had less concern about the ergonomics of space within the limited time span. In groups, having at least one student with basic-level CAD experience, they started by generating the main design idea. In this one-day workshop, we introduced the definition of magnetic behavior in the visual scripting environment of Grasshopper, followed by the implementation of the scripts to their design ideas. The final submissions were only accepted as a digital fabrication for the CAD/CAM tools available in the modeling lab at the university.

VSE, as a parametric and algorithmic digital design tool, is by no means simple to command, even for highly experienced designers. In this workshop, we focused on introducing VSE instead of showing the basics of 2D/3D digital modelling. Therefore, the students were forced to explore interrelations between their hands-on physical drawings and models, and VSE scripts.
After a brief introduction to VSE, seven groups of 4-6 students were formed from Architecture, Fashion Design, Interior Architecture and Environmental Design, Industrial Design and Visual Communication and Design. Each team member was designated to specific tasks, such as analyzing the site, developing the design idea, making sketches and mockup models of their idea, and of exploring the VSE interface further. This paper presents the step-by-step performance of each of the teams, from initial acquaintance to final analysis and graphical visualizations.

Within VSE definition for magnetic field, and predefined fabrication technique with plug-in on VSE; several teams used similar fabrication methods, with slight changes, and got their final model easily. Other, more inquisitive groups, pushed their limits to search-out more complex methods than their classmates (Group 1, Figure XX). Group 1 decided not to use the simple waffle structure, but rather the method of triangulating the surface to show the topographic changes in the model.

Having learned about file-to-factory and the simple rules to create models, the digital design process ended with Computerized Numerical Controlled (CNC) fabrication, which involved laser-cutting the cardboard elements of each model. After this creative session, the groups gathered their pieces for assembly and final presentation.

\section{Observation and Findings}

Most of the students tended to use various representation methods such as sketching, hands-on modelling or storyboards, instead of exploring design solutions via the introduced (compulsory) VSE. The students were allowed to use various representation methods during their design development phase, however, they were asked to use the laser cutter for the final submissions.

- As we observed, there was valuable correlation between the quality of final outcome and the effort that students had made during the design process via physical representation tools (Figure 3). 


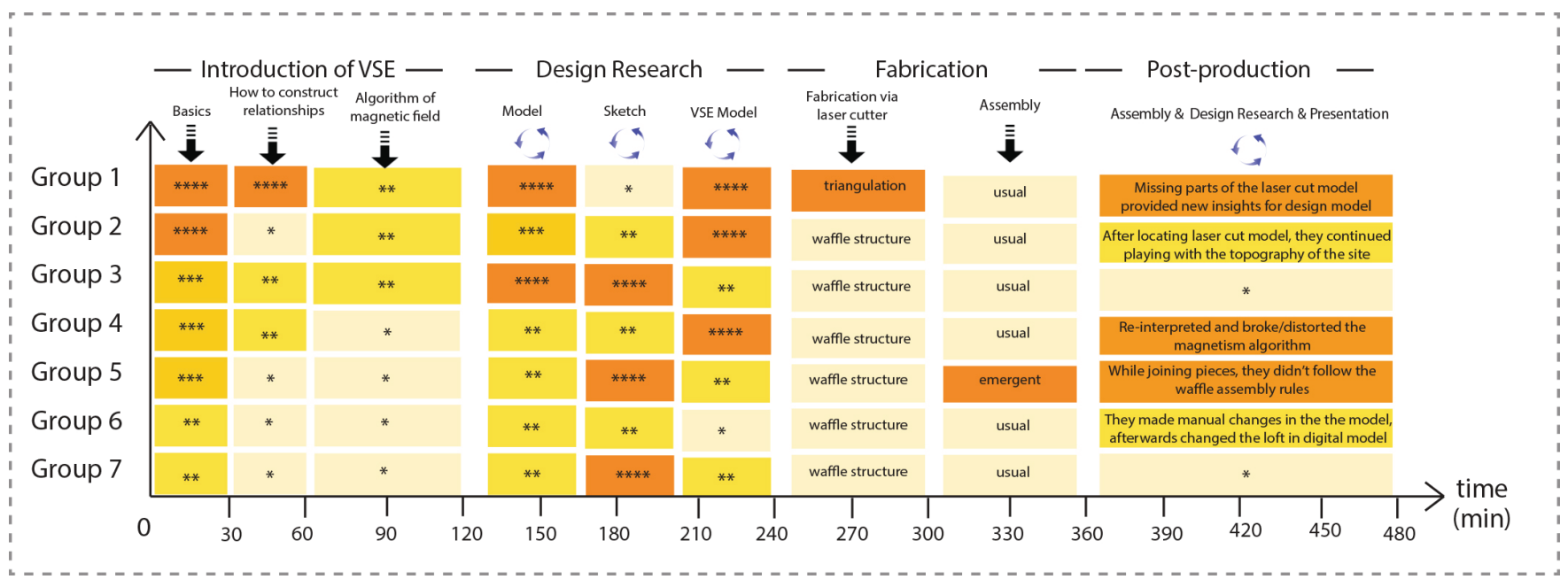

Table 1: Rating each group in different process during the workshop.

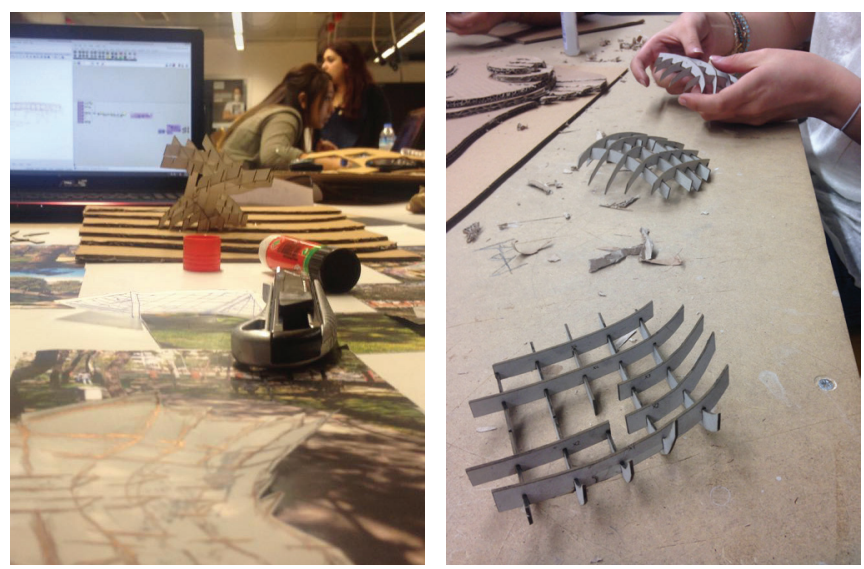

Figure 3 (Left) : Conceptual work of one of the group using sketch paper and photos to reshape the topography with collage.

Figure 4 (Right) : Assembly process of Group3.

- In addition to this, some group members were more interested in exploring VSE. This additional curiosity in VSE brought more variety to outcomes.

- With respect to VSE, students who managed to deal with the parametric interface continued exploring during the further assembly process (Group 1 and Group 5, Table 1).

- Those students also tried to evaluate or assemble in different ways than VSE ordered (Group1 and Group5, Table 1).

At the end of the course, we could have seen that every group interpreted magnetism for their own design task in various ways as listed below:

- Manipulation of the topology of playground (Group1 and Group7);

- Approaching the algorithm as an object (Group3, Group5 and Group6);

- Approaching the algorithm as a spatial configuration (Group2 and Group4).

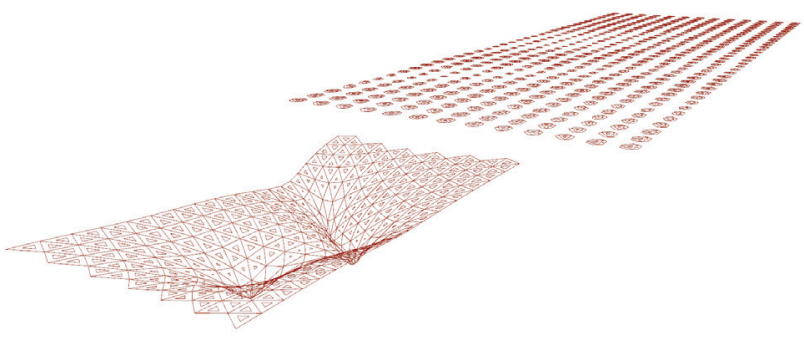

Figure 5: Screenshot from VSE outcome of Group 1.

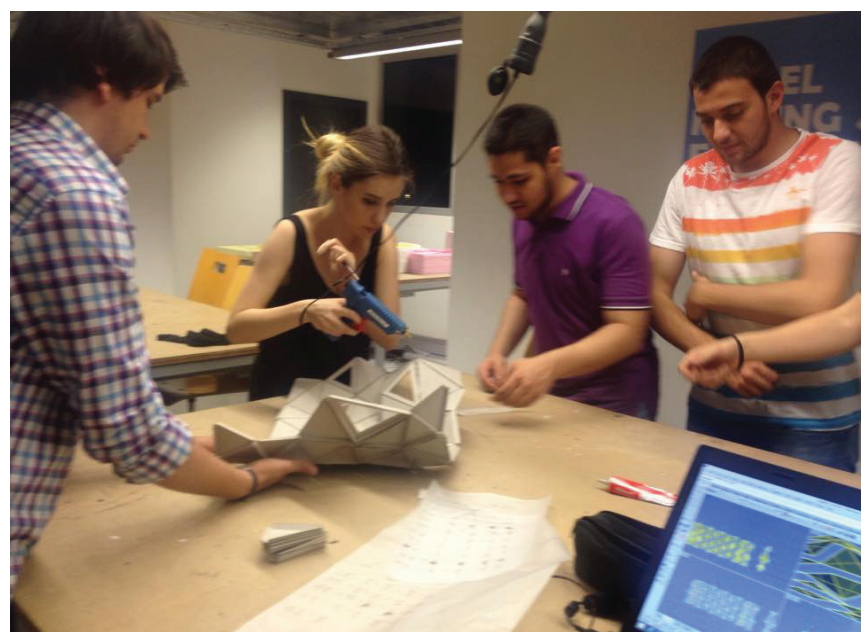

Figure 6: Assembly process of Group1; During the assembly, they continued to explore their model.

Limited experience with fabrication was another big obstacle for them but, surprisingly, one of those groups (Group 1) wanted to find different models and demand them in VSE for digital manufacturing in their final submission. These additional searches for concrete scripts began as personal challenges for diversity and produced a richer quality of outcome. 


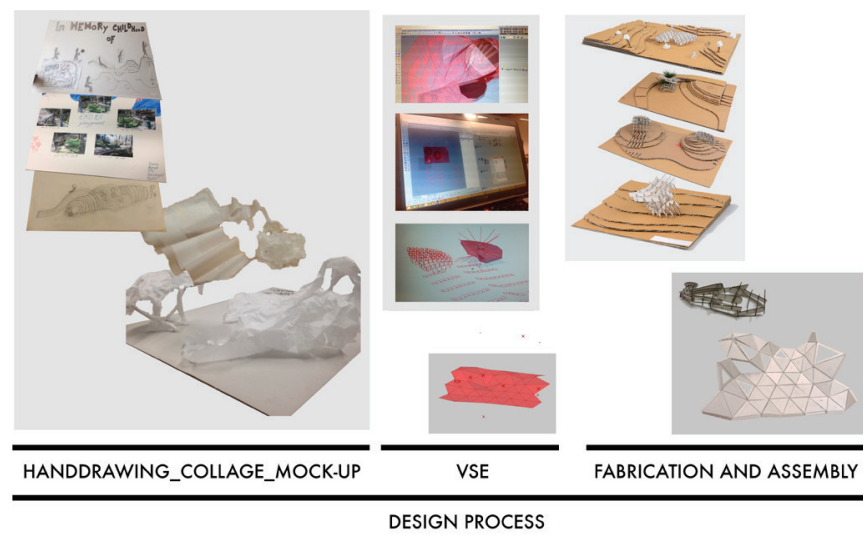

Table 2: Outcomes from several parts of design process.

Another important observation is that the CAM process allowed students to become more familiar with the limits of the materials. While inputting detail on Focus or Speed to the laser cutter, they developed an understanding of how materials can react during real production. This file to factory method didn't allow much sway from abstract thinking nor having concrete solutions.

\section{Concluding}

In conclusion, the success of this one day workshop is have a variety of design project end results within one day of training/design and fabrication. At first glance, the final products of the students have formal similarities as the script that they used had strict rules. However, when the time-span of the workshop is considered, we can say that their works were quite impressive with this limited experience. As our main goal was to convey the VSE, their exploration of the scripting language to express their creativity and innovation may come at the later period of their education.

During the workshop in the first phase the students were encouraged to develop design solutions by hands-on methods such as sketching, model making or superimposed collages. There is a valuable correlation between the quantity of the design decisions of handson session and research quality VSE models. On the other hand, this argument needs to be validated by additional comprehensive research.

\section{Acknowledgments}

Our thanks to Izmir University of Economics for financial support to the workshop; all the students of Art and Design Studio course of the year 2015. Lastly I am indebted to Tugyan Aytac Dural and Nina Kerstelli as studio coordinators of the Art and Design Studio Courses, and to Bahar Durmaz, Michael Edward Young and Altug Kasali for the assistance all along the panel in which the workshop is part of.

\section{References}

Carpo, M. (2011). The alphabet and the algorithm. MIT Press. Celani, G. (2012). Digital Fabrication Laboratories: Pedagogy and Impacts on Architectural Education. Nexus Network Journal, 14(3), 469-482, doi:10.1007/s00004-012-0120-x

Duarte, J. P., Celani, G., \& Pupo, R. (2011). Inserting computational technologies in architectural curricula. In N. Gu, \& X. Wang (Eds.), Computational Design Methods and Technologies: Applications in CAD, CAM and CAE Education (pp. 390-411). IGI Global.

Gül, L.F., \& Simisic, L. (2014). Integration of Digital Fabrication in Architectural Curricula. FabLearn Europe 2014, Digital Fabrication Conference, 16 June 2014, Aarhus University, Denmark.

Liapi, M., Oungrinis, K., \& Voyatzaki, M. (2012). Sensponsive Playscapes: A Pedagogical Design Approach to Manifest and Promote the Physical Digital Continuum. Digital Physicality -Physical Digitality (pp. 343-351), 30th eCAADe International Conference, Czech Technical University in Prague

Mark, E., Martens, B., \& Oxman, R. (2003). Preliminary stages of CAAD education. Automation in construction, 12(6), 661-670.

Oxman, R. (2006). Digital design thinking: in the new design is the new pedagogy. In CAADRIA 2006 [Proceedings of the 11th International Conference on Computer Aided Architectural Design Research in Asia] Kumamoto (Japan) March 30th (pp.37-46).

Prensky, M. (2001). Digital natives, digital immigrants part 1. On the horizon, 9(5), 1-6.

Trigwell, K., \& Prosser, M. (1996). Changing approaches to teaching: A relational perspective. Studies in Higher Education, 21(3), 275-284, doi:10.1080/03075079612331381211 Valdes, F., Cavieres, A., \& Gentry, R. (2013). A Process--Centric Approach for Teaching Digital Fabrication. Blucher Design Proceedings, 1, 400-404. Retrieved from http://pdf.blucher. com.br/designproceedings/sigradi2013/0076.pdf 